\title{
Penury and potential in Venezuela
}

\section{Maxine Clarke}

\section{Five years ago Venezuela's currency collapsed. Since then the country's researchers have been doing science on a shoestring.}

TODAy, 2 February, Venezuela acquires a new president, Carlos Andres Perez, victor of the general election held in December after a year-long campaign. He inherits a stable and, in Latin American terms, remarkably democratic political system. Since the end of the dictatorship in 1958 there has been little organized unrest, and the collapse of the guerrilla movement in the mid-1970s heralded almost ten years of stability. On 'Black

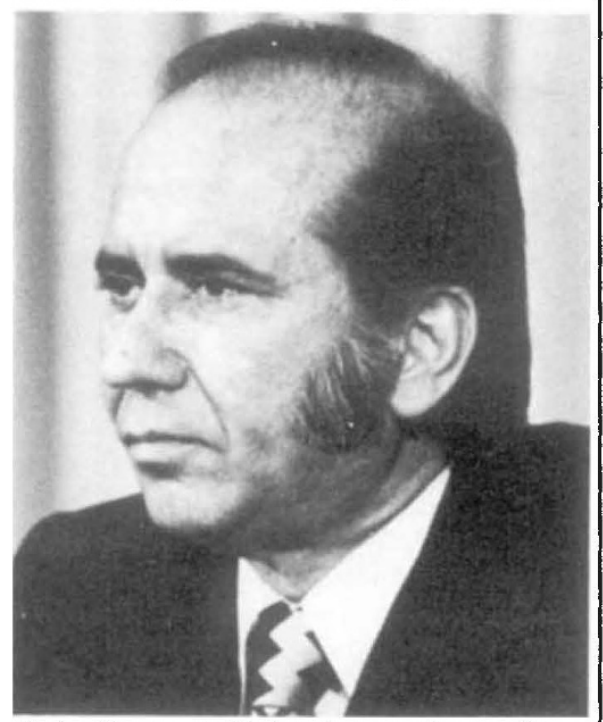

Carlos Perez - unlikely to have a science policy.

Friday' in October 1983, the currency fell from about three bolivars (Bs) to the US dollar to its present thirty-five. Almost overnight, imported goods became impossible to obtain and foreign travel became prohibitively expensive.

Before 1983, oil had propped up the country virtually unaided. But when the oil prices collapsed, escalating interest rates set by international banks crippled the economy. Another 50 per cent devaluation seems to be on the way. In his previous administration (1974-1979), Perez nationalized the oil industry and ended the social unrest of the 1960 s by inviting guerrilla leaders to join his government. Hopes that he will repeat the trick for the present crisis were pre-empted by the outgoing president Jaime Lusinchi, who last month announced that Venezuela

These articles are based on a recent visit to Venezuela by Maxine Clarke, Nature's Features Editor. Thanks are due to her host Maria Centeno, and also Carlo Caputo, Nora Castaneda, Stephen Garner-Winship, Erica Jaffe, Raul Padron and Jorge Villegas. will stop paying the principal on about $\$ 20,000$ million of its outstanding foreign debt to international banks.

Science inevitably takes a back seat in such economically crisis-ridden times. Perez will probably appoint Jaime Requena as his science minister, but the administration is unlikely to have a science policy. Some Venezuelans think this only realistic given the economic problems. Others believe that investment in research is essential for the future, particularly in developing the nascent aluminium, hydroelectric power and plastics industries.

Although there are many excellent scientists in Venezuela, the government's organization of the research effort is a shambles. Apart from CONICIT, a body

\section{The institutes: self-help is the answer}

EАCH of Venezuela's research institutes is responsible to the ministry that founded it. IVIC, the institute for scientific investigation, is the largest. Others are IDEA, the institute of advanced studies; INTEVEP, the oil institute; FONAIP, the agricultural institute; FII, the engineering institute; and CAICET, the Amazon research institute. Most of these do not support much basic research. CAICET, for example, is mainly involved in health programmes.

As in other South American countries, research in Venezuela is administered by CONICIT, which has a budget of some 180 million Bs (about \$5 million) per year. About a third of this is available to scientists who apply for grants, another third goes on students and equipment, and another third on administration. Many scientists are critical of CONICIT for spreading these meagre resources too thinly on new programmes rather than continuing to support existing projects.

Even by its rivals IVIC is said to be the best research institute in Latin America. The problems it faces are typical of the conditions faced by scientists in post-crash Venezuela. It is under the control of the minister of health, who appoints the director, who then can appoint heads of department, distribute the annual budget as he wishes and so on. The staff at IVIC elect a new director every four years, but there have been occasions when the scientists' choice has been ignored - if the candidate belongs to the wrong political party, for example. The government ministers that is Latin American rather than having evolved specifically in Venezuela, there is no organized, national system for awarding grants by scientific merit. Decisions are left up to individual directors of institutes or rectors of universities. Some of them do indeed apply professional criteria in distributing the limited funds available, but the lack of accountability means that others need not be so scrupulous. 'Administrative' costs, for example, can swallow up huge proportions of an institution's budget. Unpopular individuals can fail to have their projects supported, and projects can be supported for political, rather than scientific, reasons. Most researchers who have jobs have them for life, a situation open to abuse. themselves are often ex-scientists who have decided on a political career in order to implement their ideas about what sort of science should be done, a system that leads to frustration among those researchers who feel that their careers are being directed by people who have some grand scheme in mind, rather than those who will take notice of project applications from the grass-roots level.

This frustration has resulted in fragmentation of resources. Two breakaway institutes have been set up by IVIC scientists who in the past have disagreed with the way the institute is run: INTEVEP, which was formed by members of the chemistry department, and IDEA (see below).

IVIC receives an annual budget from the government of 300 million Bs (about $\$ 8.5$ million). There are 12 scientific departments, called centres, service departments and administrative offices. The institute also provides facilities such as accommodation, a kindergarten, a national guard post, a bank and that Venezuelan rarity, a post office.

In the past few years the budget has become inadequate for IVIC to function effectively - the money has to pay for 100 scientists, their support staff, equipment and running costs. So other sources of income are being sought. IVIC's director, the neuroscientist Horacio Vanegas, is involved in discussions with various international science organizations and the Andean Development Corporation (CAF), a biotechnology development organization. Shopping around in this fashion is 